\title{
Os fios do poema - anagramas de Beatriz H. R. Amaral
}

Ronaldo Werneck

Ítalo no talo, Calvino dixit: "O livro deveria ser a contrapartida escrita do mundo não escrito. A sua matéria devia ser aquilo que não existe nem poderá existir senão quando for escrito". Há muito não lia uma citação tão perfeita, tão soi-disant, como essa de Ítalo Calvino que Beatriz Amaral coloca como epígrafe de seu belo livro de contos "Os fios do anagrama" (RG Editores/ São Paulo, 2016). O dito de Calvino - melhor, o seu "escrito" - sobrepaira como antevisão, como proposta e razão de ser, ao longo de todas as narrativas que compõem a nova obra da autora, intelectual de longo curso: poeta, musicista, ensaísta, contista, vários e vários livros publicados em sua trajetória. "Contrapartida do mundo" (i.e., da narrativa), o livro, a sua matéria, só existe enquanto "escrita". Ao apropriar-se de Calvino como se fora um "fio narrativo" de sua escrita, Beatriz Amaral na verdade trabalha com a "escritura" no conceito lacaniano, com a criação que constrói a tessitura de sua narrativa, embasada na força de suas palavras. Elegante, sofisticada, erudita, a escritura desses contos ressalta na maioria das vezes a força da palavra, a extrema habilidade de Beatriz em manejála, sobrepondo-se à própria narrativa - prazer que, como leitor, positivamente eu não dispenso. Confesso que raramente consigo ainda me deixar levar pelo fluir de uma história, pelo plot da narrativa, de qualquer narrativa. Vício antigo, eu acabo me fixando nas palavras, em sua construção, no seu entrelaçar, nos seus entrechoques, nos seus súbitos cortes, em seus meandros. Na verdade, mais que na fôrma, no dito "conteúdo", eu acabo mesmo é privilegiando a forma, me detendo na sintaxe, na semântica, nas aliterações, metáforas, nas anáforas (para exemplificar dentro do contexto desse livro) ou outros artifícios de linguagem que Beatriz manobra muito bem dada a sua sofisticada escrita \& escritura. Fiz então com "Os fios do anagrama" o que sempre faço com os livros de que gosto: vou marcando frases, 
palavras, palavras, palavras. Assim fiz, marcando, remarcando e acabei grifando grande parte de suas páginas. Coisas assim como "por que escrever, se parte dos dados se perdeu na memória - e justamente a parte objetiva das coisas?". O que me remete ao saudoso poeta mineiro Francisco Marcelo Cabral: "Escrevemos/ porque sabemos/ que vamos morrer. // Escrevemos/ porque não sabemos/ por quê". Assim foi que copiei ("escrita") esses trechos assinalados - touchstones, punti luminosi - e os dispus em conformação de poema ("escritura"?). Não vejo melhor maneira de demonstrar o grande prazer que me proporcionou a leitura desse "Os fios do anagrama". Prazer que repasso agora aos leitores: eles certamente irão se encantar com a escrita de fino trato de Beatriz Amaral.

Fios que se refazem

"Alguém rebobina as cenas./ Pula. Rebobina. / Quem se confunde nesse Labirinto? / Quem brinca nos domínios de Mnemosine? // Crshshshsh! / Tombam no chão mais de cinquenta pequenas bússolas douradas. / As placas se fixam à esquerda do lago: / Vendemse bússolas. / Você descobre o norte. / Há uma ideia de água onde você está".

"Valladolid virá, como de costume / septiembre, septiembre, / com seu teor de véspera e seu timbre/ inusitadamente grave:/ navegarei noites/ abertas e ibéricas".// À beira do impasse,/ um mestre fisga/ o cerne da cena. // Em cada canto/ se interpenetram/ camadas de cotidiano". "Stella, anfíbio/ que sibila,/ antítese do arco.// A voz da filha/ antes do jantar:/ Mãe, libélula é/ proparoxítona?/ É. Antítese também./ Também hipérbole,/ Metáfora, parábola/ Fábula, líquido,/ Pérola, capítulo.// Ah, capítulo também./ Que palavra linda essa./ Pensava: deve ser/ Uma palavra importante./ Capítulo dezessete,/ Capítulo trinta e dois". "Um parafuso, uma espátula,/ o grampeador, o esmalte/ cor de mel.// Stella vê o passaporte./ Finge que não viu./ Não dá mais/ pra parar de procurar.// Qualquer coisa./ Qualquer coisa mesmo./ Os anéis de Saturno./ As luas de Júpiter./ O vento do mar./ Qualquer coisa/ que justifique/ a busca. Algo/ inusitado que ilumine/ a noite e apague/ o fio de luz: este desejo/ intermitente de estar/ pronta". "Laerte e Arlete/ anagramaticamente/ unidos entre os dígrafos/ de sobrenome ibérico./ Laerte submerge./ Ideias entre camadas,/ escamas e cromatismos.//Em plenilúnio/ Laerte e Arlete/ plantam planetas/no tempo.// Rápidas rotas/ 
insólitas./ É pedra de fonema./ É ritornello.// Neste portal/ de anáforas/ você se despe/ você não repete nomes/ você sabe o claro-escuro/ você recolhe/ você lendo/ você tece tão célere/ você no meio/ você se depara/ você reconstrói/ você sabe/ você ensaia/ você arquiteta/ você - aeroplanagem/ você caminha/ você Gertrude Stein/ você a rose a rose/ você a prose a prose". "Agora, o texto/ - substituto do olho/ míope e cansado -/ desliza pela página./ Por que escrever,/ se parte dos dados/ se perdeu na memória/ - justamente a parte/ objetiva das coisas?// E aqui estou,/ há três dias,/ fragmentando/ e dissolvendo/ frases não ditas, palavras sem som,/ imagens sem nome,/ mensagens sem destino,/ personagens não encenados. // Quem engendra/ o som das palavras?/ Em Los Angeles,/ a lua se remove./ O peso das sílabas,/ mel de abelhas,/ hortelã./ Escreve o dia/ Com o olho". "Estilhaços de futuro/ Não se tocam./ Um eco, nada mais,/ você é quem sabe./Vendredi, monsieur,/ vendredi./Ou jeudi?// Será o círculo/ o símbolo do self?/ Quem pergunta? Que voz/ desponta no meio/ do texto para contestar/ o conhecimento/ do esboço, do relevo, / do contexto?// Se sou poeta, escrevo,/ escrevo, escrevo/Alquimia dos Círculos./ E na transmutação/ de formas circulares,/ a dança da linguagem/ saberá extrair o seu lugar?/ Saberá escolher o porto,/ o aceno, a figura/ cromática do sono?/ Rota, modulação,/ desnível. Círculo/ delírio da noite bemol". "Algumas ondas/ rebobinam cenas e/ desenham um tempo de naus./ No inverno, as paisagens/ marinhas nos tragam,/ são intensas, espessas.// Aqui o porto das palavras se faz lento, sólido,/ Denso.//Mas é palavra/ em sua própria harpa,/ em que/ vibram os séculos/ dos séculos ao sol." Ronaldo Werneck Cataguases, Set 2017 


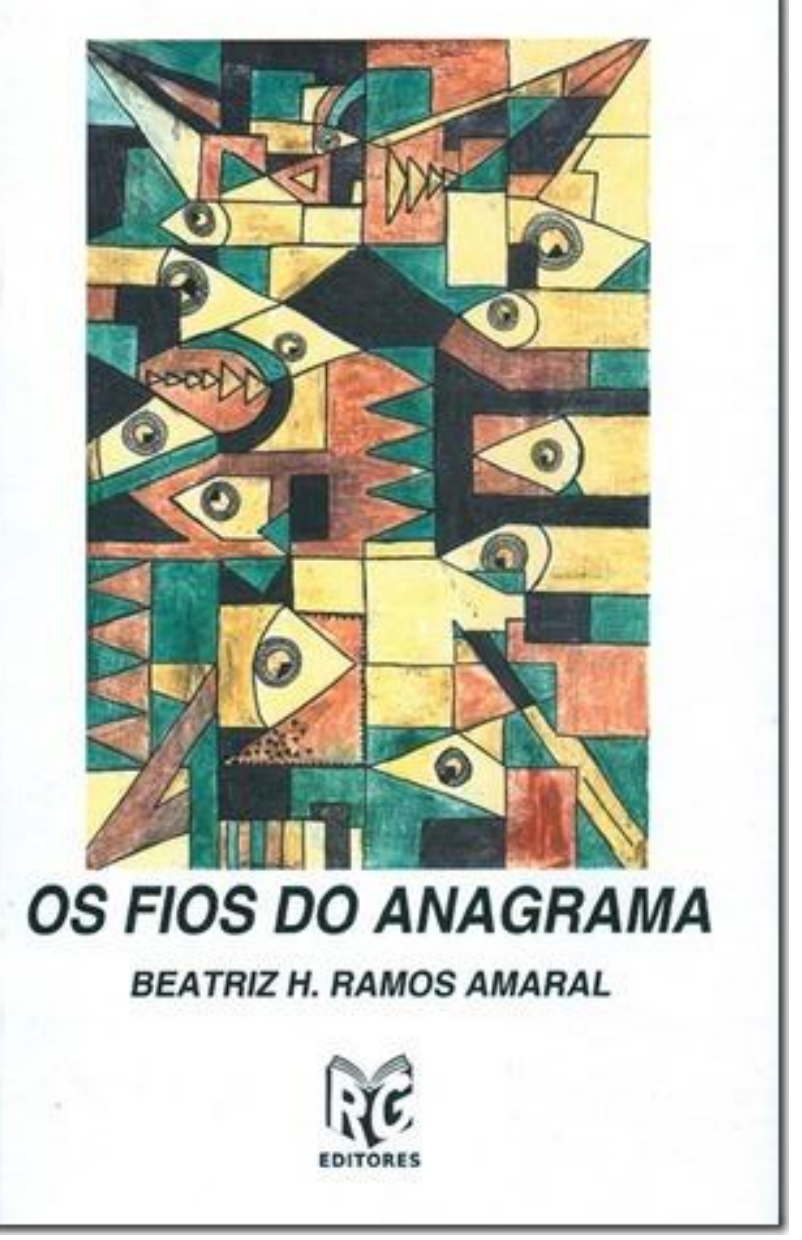

i De 1990 a 2004 foi Assessor de Comunicação e Editor de Textos do CCBB/Rio e na Fundação Cultural Ormeo Junqueira Botelho, com sede em Cataguases. De 2005 a 2010 foi Diretor de Comunicação do CINEPORT -Festival de Cinema de Países de Língua Portuguesa. Entre Entre 2002 e 2005 foi Coordenador do Centro Cultural Humberto Mauro, também em Cataguases. Embora sem um vínculo direto edita ainda os textos da Fundação Ormeo. 